\title{
The Fallacy of the Theoretical Meaning of Formative Constructs
}

\author{
Hervé Guyon ${ }^{1,2,3 *}$ \\ ${ }^{1}$ Sceaux IUT (University Institute of Technology), Université Paris-Sud, Orsay, France, ${ }^{2}$ UMR6308 Aménagement des Usages \\ des Ressources et des Espaces Marins et Littoraux, Plouzane, France, ${ }^{3}$ Centre for Research in Epidemiology and Population \\ Health (Institut National de la Santé et de la Recherche Médicale), Villejuif, France
}

Keywords: epistemology, ontology, formative measurement, theoretical meaning, empirical meaning

\section{INTRODUCTION}

The gap between advanced statistical approaches and epistemological discussion is certainly one of the most important problems in psychometrics to really improve psychological measures. An important issue in measurement models in social science is the debate about formative measurement models. For some years, the debate has been essentially focused on methodological issues. We aim in this short article to contribute to a critical discussion of formative models based on ontological discussion (theoretical meaning).

The mainstream in psychology is based on empirical realism (see: Slaney, 2001; Maraun and, 2013). This position holds that psychological attributes are realities that we seek to characterize independently from the knower, as in physics. Clearly all the discussion about formative measurement models is, more or less consciously, based on this empirical realism epistemology. In opposition to empirical realism, a pragmatist current is emerging and poses that the ontology of psychological attributes is not independent from social praxis (Maul, 2013; Allen and Clough, 2015; Maul et al., 2016; Guyon et al., 2017; Maul and McCrae, 2017). On the basis of this pragmatism epistemology, we argue that we should stop using formative measurement models, not only because of empirical issues but also for theoretical reasons.

\section{Psychological Attributes}

Dimitrios Stamovlasis,

*Correspondence:

Hervé Guyon

herve.guyon@u-psud.fr

Specialty section:

This article was submitted to Quantitative Psychology and Measurement,

a section of the journal

Frontiers in Psychology

Received: 21 December 2017 Accepted: 01 February 2018 Published: 15 February 2018

Citation:

There is active discussion about the ontology of psychological attributes. Psychological attributes are psychological properties of an individual (Markus and Bosom, 2013).

As Searle (1996) or Hacking (2000) propose, psychological attributes do not exist as entities independent from human perceptions. But they do correspond to some kind of reality. This "inbetween" position between empirical realism and constructivism (which considers psychological attributes to be a useful fiction), could be related to a new-pragmatism epistemology (Maul, 2013; Allen and Clough, 2015; Guyon et al., 2017; Maul and McCrae, 2017). A psychological attribute is a real object because a psychological attribute derives from the activity of the brain, which we can call mental processes in the sense of physical-chemical processes occurring in the brain. It is therefore possible to consider that the instantiation of the psychological attribute exists spatiotemporally, but psychological attributes "do not correspond to brain organization in a one-to-one fashion" (Barrett, 2009, p. 328). According to Zachary (2010) or Hare (2016), psychology should break with the dominant epistemology of "biological realism" (Lloyd, 2010), which considers a psychological attribute as a specific physical entity in the brain. A psychological attribute could be considered as an emergent property arising within the system of mental processes because of the new structures and functions that emerge from mental processes (Humphreys, 2008; Barrett, 2009; Fingelkurts et al., 2013; Maul, 2013; Guyon et al., 2017). The emergent property is not only a novel structure, it is also conceptually novel because we cannot describe 
the psychological attribute by the concepts used to describe the mental processes (Humphreys, 2008; Barrett, 2009, 2011; Fingelkurts et al., 2013; Maul, 2013). A psychological attribute is in consequence not reducible to mental processes in a predictable or non-reductionist way (Barrett, 2009; Maul, 2013).

The reality (and conceptualization) of a psychological attribute resides in its functional appearance and is derived from human experience and social interactions (Hacking, 2000; Maul, 2013; Guyon et al., 2017). The categories used in psychology (psychological concepts) are observer-dependent (Searle, 1996). Psychological attributes are classified according to their manifestations and their function in social communication (Barrett, 2009). These categories are linked to physical realities, but physical reality is not only what is in the brain, because physical reality also entails social interaction (Thompson and Varela, 2001; Hare, 2016). A concept in psychology can thus be considered as referring neither to a fixed reality (external from social praxis), nor to a singular construction independent from physical reality (Maul, 2013). The categories used in psychology are relational entities, interactive genres (Hacking, 2000).

This pragmatist epistemology is not a radical relativist or constructivist position, because there is a material reality of a psychological attribute, but it is "a new pattern of reality" (Fingelkurts et al., 2013, p. 5) that can only be understood as a holistic reality formed by inter-subjective interaction (Varela et al., 1992; Thompson and Varela, 2001; Fingelkurts et al., 2013; Guyon et al., 2017). This is not a criticism of neurobiology, but neurobiology and experimental psychology are in two incommensurable paradigms in the sense given by Kuhn or Feyerabend.

\section{Empirical Meaning and Theoretical Meaning of Formative Measurement Models}

The core of the discussion on formative measurement models has been the "empirical meaning" of such measures. With a few exceptions (Bollen and Diamantopoulos, 2017), most authors consider now that formative measurement is irrelevant because the empirical meaning is a fallacy (Edwards, 2011; Rhemtulla et al., 2015; Aguirre-Urreta et al., 2016a; Bentler, 2016; Cadogan and Lee, 2016; Guyon and Tensaout, 2016; Howell and Breivik, 2016; Lee and Chamberlain, 2016; Markus, 2016; Hardin, 2017). But the academic literature seems to consider the idea that "constructs themselves, posited under a realist philosophy of science as existing apart from their measurement, are neither formative nor reflective" (Wilcox et al., 2008, p. 1220) as providing "evidence." Bagozzi (2011) for example proposed a synthesis on construct measurement and considered that the theoretical meaning of a formative construct does not differ in nature from a reflective construct; their meanings diverge only on the empirical level. Similarly Hardin (2017, p. 598) wrote: "Constructs exist independently from their measures; theory determines whether indicators cause or measure latent variables." Aguirre-Urreta et al. (2016a, p. 77) likewise stated: "Constructs are concepts whose meaning is provided by the researcher as part of the conceptualization process, which precedes any considerations of how the construct is to be measured."

Burt (1976) was the first to highlight the significance of distinguishing between the nominal and the empirical meaning of a construct. The nominal meaning is the interpretation initially postulated by the practitioner. On the basis of "auxiliary theory" (Sajtos and Magyar, 2016), the empirical meaning is that obtained once the measurement model used to represent the construct has been assessed. When these two meanings differ, the specified measures are then subject to interpretational confounding, which appears as the core of the problem with causal indicators (Howell et al., 2007; Aguirre-Urreta et al., 2016a). But how should a construct represented by causal indicators be apprehended theoretically? With a formative measure, we do not observe manifestations of a real (or supposedly real) entity, we hypothesize that an unobservable entity is defined by "causal indicators."

\section{The Ontological Status of Psychological Attributes Measured Formatively}

MIMIC models are rarely used in applied research (Aguirre-Urreta et al., 2016b). Thus, formative constructs discussed here have no manifest variables, but only causal indicators. A formative construct of this sort cannot be modeled without affecting other reflexive latent variables (Figure 1).

It should be noted that eta must refer to a real entity and cannot be considered as a pure construction. If eta is prespecified by the researcher (as a non-realist entity), eta cannot have an error term (kis1), and becomes an index (Bollen, 2011). As Bollen and Diamantopoulos (2017) recalled: a latent variable related to a real entity with an error term of zero can occur under certain special circumstances, but this is however extremely unlikely in practice (Bollen and Diamantopoulos, 2017).

The central question discussed here is the theoretical legitimacy of eta in the model (Figure 1). In Figure 1, both eta1 and eta 2 refer to psychological attributes that have theoretical meaning because they represent (in the statistical model) psychological attributes that have observable manifestations (represented by the Ys). But eta (the formative latent variable) relates to an entity that has no observable manifestation. This is the ontological issue.

A psychological attribute is a psychological property of an individual, and it can be an entity that exists only in the social space. A psychological attribute exists if and only if it has perceptible manifestations; if not, nobody can consider that a particular attribute characterizes a specific person. A psychological attribute must therefore have manifestations in order to be "real" in our social praxis: "the appearance is the reality" (Maul, 2013, p. 757). The conceptualization, and therefore the measurement approach, must start from the perceptible manifestations of the psychological attribute, which underpin the theoretical meaning. In consequence, only a reflective measurement model based on perceptible manifestations can be used to link a latent variable (empirical meaning) to a concept (theoretical meaning) (Guyon et al., 2017). 


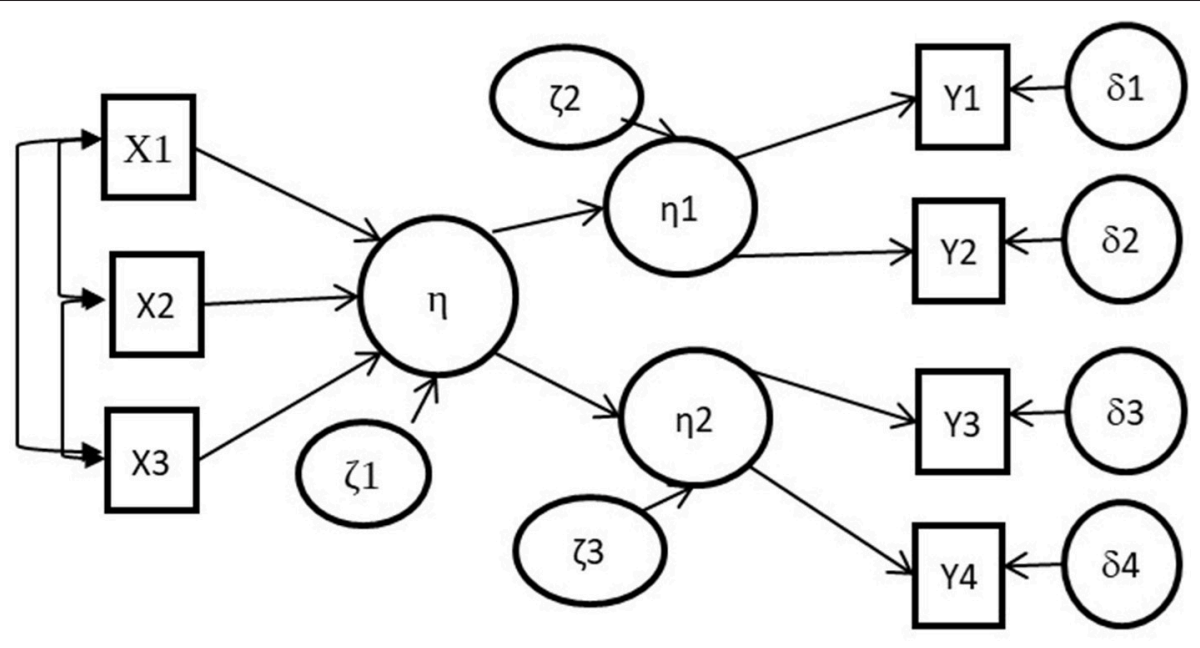

FIGURE 1 | A formative latent variable links to two reflective latent variables.

The hypothetical entity referred to as eta has no perceptible manifestations in the Figure 1. Because this entity is linked to the psychological attributes represented by eta1 and eta2, we must consider that the entity represented by eta is an entity underpinning psychological attributes: an entity in the brain that generates other psychological attributes which in turn generate perceptible manifestations. Except for very rare psychological attributes, entities in the brain underpinning psychological attributes are not fixed entities. So, eta relates to mental processes, physical-chemical processes underpinning psychological attributes. Eta1 and eta2 are emergent properties. In a linear model we cannot link eta (mental processes) to eta 1 and eta2 (psychological attributes) because the psychological attributes that emerge from mental processes are not reducible to the mental processes in a predictable or non-reductionist way. These are incommensurable paradigms: mental processes are what is in the brain, psychological attributes are what is in the social space. This is the reason why, generally, models with psychological attributes do not introduce "mental processes" into the models, but tend only to model (linear) relations between psychological attributes. Concretely, in the overall model (Figure 1) eta relates to a psychological attribute in a realist epistemology, and at the same time eta cannot relate to a psychological attribute. So we need to remove eta from the model.

Common examples of formative measurement models are "exposure to discrimination" and "Socio-Economic Status" (SES). It may be that a "perception of socio-economic status" or a "feeling of discrimination" (or "belief in one's socio-economic status" or "belief in discrimination") can be experienced by individuals, and that these psychological attributes could generate perceptible manifestations. Clearly, a "feeling of discrimination" or a "perception of Socio-Economic Status" are not the same objects as actual "exposure to discrimination" or "Socio-Economic Status." We are not saying that there is no reality in "exposure to discrimination" or "SocioEconomic Status," and they can therefore be conceptualized; but they are not psychological attributes because they have no perceptible manifestations conceptually linked to these constructs. Certain social or personal characteristics could generate certain psychological characteristics in an individual, but as Lee and Chamberlain (2016) recalled, causal indicators do not determine the meaning of psychological attributes, they are only their causes. These sociological concepts are not psychological characteristics of a person (as a "perception of socio-economic status" or a "feeling of discrimination" can be), and they can be formalized in a statistical model, on the basis of causal indicators, using an index (without error term ksil in Figure 1), but not using a latent variable.

\section{CONCLUSION}

Widaman (2014) considers that a formatively measured psychological attribute can be considered as an "emergence" of its indicators. We consider that psychological attributes are emergent properties of an individual. But an emergent property is a reality because it exists through empirical manifestations. The emergent property of a formative construct referred to by Widaman has no empirical manifestations (eta1 and eta2 in Figure 1 are not empirical manifestations), and so we consider that this use of the emergence concept is in this instance an explanatory artifice. Psychological attributes are derived from human experience; the concept (theoretical meaning) results from perceptible manifestations of an emergent property (the psychological attribute) and therefore the empirical meaning (latent variable) must necessarily be linked to a reflective measurement model. Our position does not deny that there can be exogenous factors (causal indicators) that could influence psychological attributes, but these exogenous factors cannot be considered as providing the theoretical meaning of a psychological attribute. Only perceptible (reflexive) manifestations can drive the meaning of a psychological attribute. 


\section{AUTHOR CONTRIBUTIONS}

The author confirms being the sole contributor of this work and approved it for publication.

\section{REFERENCES}

Aguirre-Urreta, M. I., Rönkkö, M., and Marakas, G. M. (2016a). Omission of causal indicators: consequences and implications for measurement. Meas. Interdiscip. Res. Perspect. 14, 75-97. doi: 10.1080/15366367.2016.1205935

Aguirre-Urreta, M. I., Rönkkö, M., and Marakas, G. M. (2016b). Omission of causal indicators: consequences and implications for measurement - a rejoinder. Meas. Interdiscip. Res. Perspect. 14, 170-175. doi: $10.1080 / 15366367.2016 .1257323$

Allen, P. M., and Clough, S. (2015). Philosophical commitments, empirical evidence, and theoretical psychology. Theory Psychol. 25, 3-24. doi: $10.1177 / 0959354314563324$

Bagozzi, R. P. (2011). Measurement and meaning in information systems and organizational research: methodological and philosophical foundations. MIS Q. 35, 261-292. doi: 10.2307/23044044

Barrett, L. F. (2009). The future of psychology: connecting mind to brain. Perspect. Psychol. Sci. 4, 326-339. doi: 10.1111/j.1745-6924.2009.01134.x

Barrett, L. F. (2011). Bridging token identity theory and supervenience theory through psychological construction. Psychol. Inq. 22, 115-127. doi: 10.1080/1047840X.2011.555216

Bentler, P. M. (2016). Causal indicators can help to interpret factors. Meas. Interdiscip. Res. Perspect. 14, 98-100. doi: 10.1080/15366367.2016.1224964

Bollen, K. A. (2011). Evaluating effect, composite, and causal indicators in structural equation models. MIS Q. 35, 359-372. doi: 10.2307/23044047

Bollen, K. A., and Diamantopoulos, A. (2017). In defense of causalformative indicators: a minority report. Psychol. Methods 22, 581-596. doi: $10.1037 /$ met0000056

Burt, R. S. (1976). Interpretational confounding of unobserved variables in structural equation models. Sociol. Methods Res. 5, 3-52. doi: $10.1177 / 004912417600500101$

Cadogan, J. W., and Lee, N. (2016). Distinguishing valid from invalid causal indicator models. Meas. Interdiscip. Res. Perspect. 14, 162-166. doi: $10.1080 / 15366367.2016 .1264235$

Edwards, J. R. (2011). The fallacy of formative measurement. Organ. Res. Methods 14, 370-388. doi: 10.1177/1094428110378369

Fingelkurts, A. A., Fingelkurts, A. A., and Neves, C. F. H. (2013). Consciousness as a phenomenon in the operational architectonics of brain organization: criticality and self-organization considerations. Chaos Solitons Fractals 55, 13-31. doi: 10.1016/j.chaos.2013.02.007

Guyon, H., Falissard, B., and Kop, J. L., (2017). Modeling psychological attributes in psychology - an epistemological discussion: network analysis vs. latent variables. Front. Psychol. 8:798. doi: 10.3389/fpsyg.2017.00798

Guyon, H., and Tensaout, M. (2016). Are formative indicators superfluous? An extension of aguirre-urreta, rönkkö, and marakas analysis. Meas. Interdiscip. Res. Perspect. 14, 101-104. doi: 10.1080/15366367.2016.1224966

Hacking, I. (2000). The Social Construction of What? Cambridge, MA: Harvard University Press.

Hardin, A. (2017). A call for theory to support the use of causal-formative indicators: a commentary on bollen and diamantopoulos. Psychol. Methods 22, 597-604. doi: 10.1037/met0000115

Hare, R. (2016). Hybrid psychology as a human science. Theory Psychol. 26, 632-646. doi: 10.1177/0959354316674374

Howell, R. D., and Breivik, E. (2016). Causal indicator models have nothing to do with measurement. Meas. Interdiscip. Res. Perspect. 14, 167-169. doi: 10.1080/15366367.2016.1251271

Howell, R. D., Breivik, E., and Wilcox, J. B. (2007). Reconsidering formative measurement. Psychol. Methods 12, 205-218. doi: 10.1037/1082-989X.12.2.205

\section{FUNDING}

This work received a research grant from the Commission de Recherche, IUT de Sceaux.

Humphreys, P. (2008). Computational and conceptual emergence. Philos. Sci. 75, 584-594. doi: 10.1086/596776

Lee, N., and Chamberlain, L. (2016). Pride and prejudice and causal indicators. Meas. Interdiscip. Res. Perspect. 14, 105-109. doi: $10.1080 / 15366367.2016 .1227681$

Lloyd, D. (2010). Grand challenges in theoretical and philosophical psychology: after psychology? Front. Psychol. 1:9. doi: 10.3389/fpsyg.2010.00009

Maraun, M. D., and Gabriel (2013). Illegitimate concept equating in the partial fusion of construct validation theory and latent variable modeling. New Ideas Psychol. 31, 33-42. doi: 10.1016/j.newideapsych.2011. 02.006

Markus, K. A. (2016). Causal measurement models: can criticism stimulate clarification? Meas. Interdiscip. Res. Perspect. 14, 110-113. doi: 10.1080/15366367.2016.1224965

Markus, K. A., and Bosom, D. (2013). Frontiers of Test Validity Theory: Measurement, Causation, and Meaning. New York, NY: Routledge/Taylor \& Francis Group.

Maul, A. (2013). On the ontology of psychological attributes. Theory Psychol. 23, 752-769. doi: 10.1177/0959354313506273

Maul, A., and McCrae, J. (2017). As pragmatic as theft over honest toil: disentangling pragmatism from operationalism. Meas. Interdiscip. Res. Perspect. 15, 2-4. doi: 10.1080/15366367.2017.1342484

Maul, A., Torres Irribarra, D., and Wilson, M. (2016). On the philosophical foundations of psychological measurement. Measurement 79, 311-320. doi: 10.1016/j.measurement.2015.11.001

Rhemtulla, M., van Bork, R., and Bosom, D. (2015). Calling models with causal indicators "Measurement Models" implies more than they can deliver. Meas. Interdiscip. Res. Perspect. 13, 59-62. doi: 10.1080/15366367.2015.1016343

Sajtos, L., and Magyar, B. (2016). Auxiliary theories as translation mechanisms for measurement model specification. J. Bus. Res. 69, 3186-3191. doi: 10.1016/j.jbusres.2015.12.007

Searle, J. R. (1996). The Construction of Social Reality. London: Penguin Books.

Slaney, K. L. (2001). On empirical realism and the defining of theoretical terms. $J$. Theor. Philos. Psychol. 21, 132-152. doi: 10.1037/h0091202

Thompson, E., and Varela, F. J. (2001). Radical embodiment: neural dynamics and consciousness. Trends Cogn. Sci. 5, 418-425. doi: 10.1016/S1364-6613(00)01750-2

Varela, F. J., Thompson, E. T., and Rosch, E. (1992). The Embodied Mind: Cognitive Science and Human Experience. Cambridge, MA: The MIT Press.

Widaman, K. F. (2014). Much ado about nothing_or at best, very little. Meas. Interdiscip. Res. Perspect. 12, 165-168. doi: 10.1080/15366367.2014.980109

Wilcox, J. B., Howell, R. D., and Breivik, E. (2008). Questions about formative measurement. J. Bus. Res. 61, 1219-1228. doi: 10.1016/j.jbusres.2008.01.010

Zachary, P. (2010). The abandonment of latent variables: philosophical considerations. Behav. Brain Sci. 33, 177-178. doi: 10.1017/S0140 $525 \mathrm{X} 10000841$

Conflict of Interest Statement: The author declares that the research was conducted in the absence of any commercial or financial relationships that could be construed as a potential conflict of interest.

Copyright (C) 2018 Guyon. This is an open-access article distributed under the terms of the Creative Commons Attribution License (CC BY). The use, distribution or reproduction in other forums is permitted, provided the original author $(s)$ and the copyright owner are credited and that the original publication in this journal is cited, in accordance with accepted academic practice. No use, distribution or reproduction is permitted which does not comply with these terms. 